\title{
BaAuP and BaAuAs, Synthesis via Disproportionation of Gold upon Interaction with Pnictides as Bases
}

\begin{tabular}{|r|l|}
\hline Journal: & Zeitschrift für Anorganische und Allgemeine Chemie \\
\hline Manuscript ID: & zaac. 200900070 \\
\hline Wiley - Manuscript type: & Communication \\
\hline Date Submitted by the \\
Author: & 29-Jan-2009 \\
\hline Complete List of Authors: & $\begin{array}{l}\text { Nuss, Jürgen; Max-Planck-Institute for Solid State Research, } \\
\text { Chemistry III }\end{array}$ \\
\hline Keywords: & $\begin{array}{l}\text { Gold, Ternary pnictides, Alkaline earth metals, Conducting } \\
\text { materials, Crystal structures }\end{array}$ \\
\hline
\end{tabular}

\section{scholarONE" \\ Manuscript Central}


DOI: 10.1002/zaac.200((will be filled in by the editorial staff))

\title{
BaAuP and BaAuAs, Synthesis via Disproportionation of Gold upon Interaction with Pnictides as Bases
}

\author{
Jürgen Nuss, ${ }^{[a]}$ and Martin Jansen ${ }^{[a]}$
}

Keywords: Gold; Ternary pnictides; Alkaline earth metals; Conducting materials; Crystal structures

Abstract. Gold disproportinates in the presence of the Zintl phases $\mathrm{Ba}_{3} \mathrm{P}_{2}$ or $\mathrm{Ba}_{3} \mathrm{As}_{2}$ forming $\mathrm{BaAuP}$ and $\mathrm{BaAuAs}$, respectively, and $\mathrm{BaAu}_{2}$. The air and moisture sensitive ternary compounds crystallize in the $\mathrm{ZrBeSi}$ type of structure, an ordered variant of $\mathrm{AlB}_{2}$ : $\mathrm{BaAuP}\left(P 6_{3} / m m c ; a=440.68(6) \mathrm{pm} ; c=899.8(2) \mathrm{pm} ; R_{1}=\right.$ $0.0237 ; 183$ independent reflections); BaAuAs $\left(P 6_{3} / m m c ; a=\right.$ 453.53(5) pm; $c=902.7(1) \mathrm{pm} ; R_{1}=0.0255 ; 168$ independent reflections).

* $\quad$ Prof. Dr. M. Jansen

Fax: +49-711-689-1502

E-mail: M.Jansen@fkf.mpg.de

[a] Max-Planck-Institut für Festkörperforschung

Heisenbergstr. 1

D-70569 Stuttgart, Germany

\section{Introduction}

Ascribing to gold certain halogen-like behaviours has become a well established view in solid state chemistry [1]. Impressive factual evidence is provided by the isostructural couples of $\mathrm{Ba}_{8} \mathrm{As}_{5} \mathrm{Au}$ [2] and $\mathrm{Ba}_{8} \mathrm{P}_{5} \mathrm{Cl}$ [3], [ $\left.\mathrm{NMe}_{4}\right] \mathrm{Au}$ and $\left[\mathrm{NMe}_{4}\right] \mathrm{Br}$ [4], or $\mathrm{Rb}_{5}\left[\mathrm{AuO}_{2}\right] \mathrm{Au}_{2}$ [5] and $\mathrm{K}_{5}\left[\mathrm{AuO}_{2}\right] \mathrm{I}_{2}$ [6]. The auride anion acting as an acceptor in a $\mathrm{N}-\mathrm{H} \cdots \mathrm{Au}^{-}$ hydrogen bond is displaying further halide-like behaviour [7]. Finally, gold and halogens, both can disproportionate in the presence of bases $[5,8]$.

We have tried to use gold as an oxidizing reagent for Zintl phases, in analogy to e.g. iodine which oxidizes phosphorous in $\mathrm{Ba}_{3} \mathrm{P}_{2}$ forming $\mathrm{BaI}_{2}$ and $\mathrm{Ba}_{3} \mathrm{P}_{3} \mathrm{I}_{2}$, or $\mathrm{Ba}_{5} \mathrm{P}_{5} \mathrm{I}_{3}$, respectively [9]. However, when reacting gold with $\mathrm{Ba}_{3} \mathrm{P}_{2}$, aiming at ${ }^{-} \mathrm{Ba}_{3} \mathrm{P}_{3} \mathrm{Au}_{2}{ }^{\prime}$ or ${ }^{\prime} \mathrm{Ba}_{5} \mathrm{P}_{5} \mathrm{Au}_{3}$ ', instead gold disproportionated, yielding a two-phase product consisting of $\mathrm{BaAu}_{2}$ and $\mathrm{BaAuP}$.

\section{Results and Discussion}

The Zintl phases $\mathrm{Ba}_{3} \mathrm{X}_{2}(\mathrm{X}=\mathrm{P}, \mathrm{As})$, containing isolated $\mathrm{X}^{3-}$ ions, react with gold, and a two-phase product consisting of $\mathrm{BaAuX}$ and $\mathrm{BaAu}_{2}$ in an approximate molar ratio of $2: 1$ is formed quantitatively. Figure 1 shows the powder pattern of the product mixture. The power of reduction of $\mathrm{X}^{3-}$ is not sufficient to achieve the formation of $\mathrm{Au}^{-}$anions together with $\mathrm{X}^{2-}$ or $\mathrm{X}^{1-}$ species. Such a redox process would have been necessary for obtaining a hypothetic compound ' $\mathrm{Ba}_{3} \mathrm{P}_{3} \mathrm{Au}_{2}$ '. Instead elemental gold disproportionates under these conditions, with $\mathrm{X}^{3-}$ acting as a base, according to equations (1) and (2).
Both compounds, which are accessible as pure phases by reacting $\mathrm{BaP}$, or $\mathrm{BaAs}$, with $\mathrm{Au}$, can be classified as poor metallic conductors.

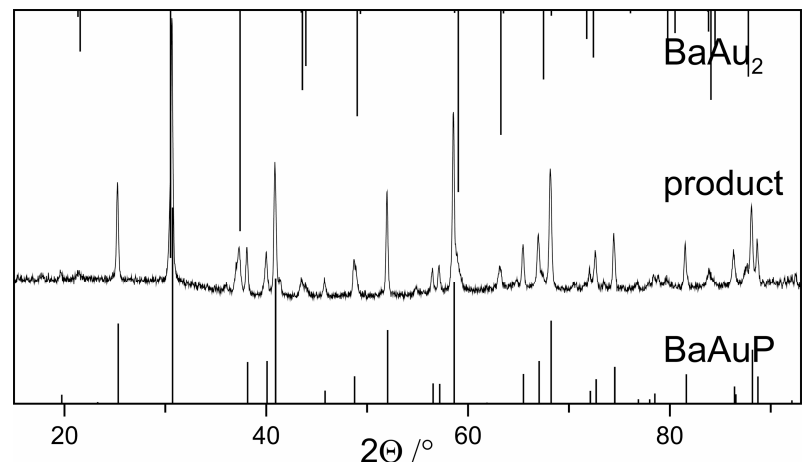

Figure 1. Powder diffraction pattern of the reaction product between $\mathrm{Ba}_{3} \mathrm{P}_{2}$ and $\mathrm{Au}$ (middle), with calculated intensity plots of $\mathrm{BaAu}_{2}$ (top) and $\mathrm{BaAuP}$ (bottom). For clarity, the intensities (arbitrary units) are drawn in positive direction for BaAuP and the product, and in negative direction for $\mathrm{BaAu}_{2}$.

$$
\begin{aligned}
& \mathrm{Ba}_{3} \mathrm{P}_{2}+4 \mathrm{Au}^{ \pm 0} \rightarrow 2 \mathrm{BaAu}^{+1} \mathrm{P}+\mathrm{BaAu}^{-1}{ }_{2} \\
& \mathrm{Ba}_{3} \mathrm{As}_{2}+4 \mathrm{Au}^{ \pm 0} \rightarrow 2 \mathrm{BaAu}^{+1} \mathrm{As}+\mathrm{BaAu}^{-1}{ }_{2}
\end{aligned}
$$

The formation of $\mathrm{BaAu}_{2}$ as a by-product can be avoided by using $\mathrm{BaX}$ as starting material. In this case pure samples of $\mathrm{BaAuP}$ and BaAuAs were obtained, which have been used for conductivity measurements. The specific electrical resistivity of BaAuP (BaAuAs) increases from 0.076 (0.041) $\Omega \mathrm{cm}$ at $5 \mathrm{~K}$ to $0.137(0.052) \Omega \mathrm{cm}$ at $300 \mathrm{~K}$, thus displaying a typical behaviour of a poor metallic conductor (Fig. 2). Because of the metallic conductivity a description $\mathrm{Ba}^{+2} \mathrm{Au}^{+1} \mathrm{X}^{-3}$ would not be valid in a strict sense; this should result in semiconducting behaviour. In equations (1) and (2) conventional oxidation states are given with the signs indicating the correct polarisation: gold has a positive charge $\left(\mathrm{Au}^{+\delta}\right)$ in $\mathrm{BaAuX}$ and a negative one $\left(\mathrm{Au}^{-\delta}\right)$ in $\mathrm{BaAu}_{2}$. 


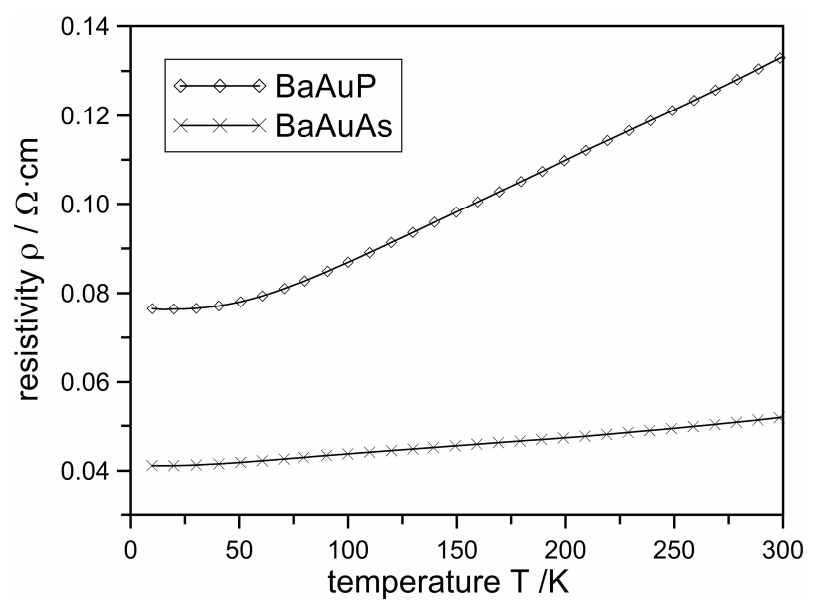

Figure 2. Electric resistivity vs. temperature for $\mathrm{BaAuP}$ and BaAuAs.

Both, BaAuP and BaAuAs, crystallize in the space group $P 6_{3} / m m c$ (no. 194, Pearson code $h P 6$ ) as was found by determination of the lattice constants from powder diffraction data, previously [10]. The structure represents an ordered variant of the $\mathrm{AlB}_{2}$ type of structure, similar to $\mathrm{ZrBeSi}$. Complex anions ${ }_{\infty}^{2}[\mathrm{AuX}]^{2-}$ are forming sheets corresponding to hexagonal boron nitride, with the barium cations in-between (Fig. 3), resulting in a $6+6$ coordination for $\mathrm{Ba}$, and a mutual trigonal planar coordination for the pnictides and gold atoms (Table 1).

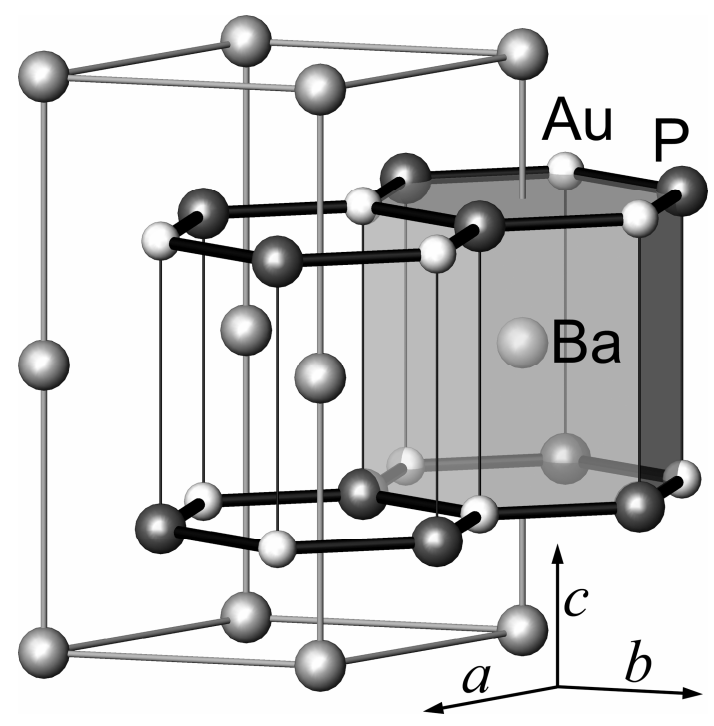

Figure 3. Perspective representation of the crystal structure of $\mathrm{BaAuP}$, with the margins of the unit cell (grey).

Table 1. Interatomic distances $/ \mathrm{pm}$ for $\mathrm{BaAuX}, \mathrm{X}=\mathrm{P}$, As (standard deviations).

\begin{tabular}{ccllc}
\hline & Atomic contact & BaAuP & BaAuAs & multiplicity \\
\hline $\mathrm{Au}$ & $-\mathrm{X}$ & $254.42(3)$ & $261.84(3)$ & 3 \\
& $-\mathrm{Ba}$ & $339.61(4)$ & $345.68(3)$ & 6 \\
$\mathrm{Ba}$ & $-\mathrm{X}$ & $339.61(4)$ & $345.68(3)$ & 6 \\
& $-\mathrm{Au}$ & $339.61(4)$ & $345.68(3)$ & 6 \\
$\mathrm{X}$ & $-\mathrm{Au}$ & $254.42(3)$ & $261.84(3)$ & 3 \\
& $-\mathrm{Ba}$ & $339.61(4)$ & $345.68(3)$ & 6 \\
\hline
\end{tabular}

\section{Conclusions}

$\mathrm{BaAuP}$ and $\mathrm{BaAuAs}$ have been synthesized by solid state reactions from $\mathrm{Ba}_{3} \mathrm{X}_{2}(\mathrm{BaX})$ and gold. The reaction products have been characterized by powder diffraction, single crystal diffraction and resistivity measurements. It has been demonstrated that elemental gold disproportionates in the presence of pnictides $\mathrm{Ba}_{3} \mathrm{X}_{2}$, whereby the pnictides are acting as bases.

\section{Experimental Section}

\section{Synthesis}

The $\mathrm{BaAuX}(\mathrm{X}=\mathrm{P}, \mathrm{As})$ compounds were prepared by the reaction of $\mathrm{Ba}_{3} \mathrm{X}_{2}$ and $\mathrm{Au}$ (1:4), with $\mathrm{BaAu}_{2}$ as a by-product in stoichiometric amounts. An optimized synthesis, realised by the reaction of $\mathrm{BaX}$ with elemental gold, leads to pure samples of $\mathrm{BaAuP}$ and BaAuAs. The barium pnictides were prepared from the elements in corundum crucibles. The crucibles were sealed in quartz ampoules, and heated at $1020 \mathrm{~K}$ for $48 \mathrm{~h}$.

Stoichiometric amounts of $\mathrm{BaX}$ and gold powder (fine $\mathrm{Au}$ powders can be obtained as described previously [11]) were mixed in a dry-box (MBraun, Garching, Germany) in an argon atmosphere $\left(<0.1 \mathrm{ppm} \mathrm{O}_{2}, \mathrm{H}_{2} \mathrm{O}\right)$ and sealed in tantalum ampoules. The reaction was carried out with the following temperature profile: $298 \rightarrow 1220 \mathrm{~K}\left(50 \mathrm{~K} \mathrm{~h}^{-1}\right.$, subsequent annealing for $48 \mathrm{~h}$ ); $1220 \rightarrow 298 \mathrm{~K}\left(50 \mathrm{~K} \mathrm{~h}^{-1}\right)$.

The solidified black reguli are sensitive to humid air and must be handled in an inert atmosphere.

\section{$X$-ray Analysis}

All samples were examined by X-ray powder diffraction. Powder patterns were collected with a linear position-sensitive detector on a STADI P diffractometer in Debye-Scherrer geometry, with Gemonochromated $\mathrm{MoK} \alpha_{1}$ radiation, $\lambda=1.540598 \AA, 5<2 \theta<100^{\circ}$ (Stoe \& Cie GmbH, Darmstadt, Germany). Samples were sealed in glass capillaries of $0.3 \mathrm{~mm}$ diameter.

For single crystal X-ray diffraction experiments, black single crystals were selected in a dry-box and mounted in sealed glass capillaries. Data collection, at 296(2) K, was carried out on a STADI4 four circle diffractometer (Stoe \& Cie GmbH, Darmstadt, Germany) and a Smart $1000 \mathrm{~K}$ three circle diffractometer (Bruker AXS, Karlsruhe, Germany), respectively. The structures were solved by direct methods and refined by full-matrix least squares using the SHELXTL program package [12]. Experimental details are given in Table 2, atomic coordinates and anisotropic displacement parameters are given in Table 3 and 4 . 
Table 2. Crystal data and structure refinement data of BaAuP and BaAuAs.

\begin{tabular}{lll}
\hline & BaAuP & BaAuAs \\
\hline Formula weight & 365.28 & 409.23 \\
Space group (no.), $Z$ & $P 6_{3} / m m c(194), 2$ & $P 6_{3} / m m c(194), 2$ \\
Lattice constants $/ \mathrm{pm}$ & $a=440.68(6)$ & $453.53(5)$ \\
& $c=899.8(2)$ & $902.7(1)$ \\
& $c / a=2.042$ & 1.990 \\
$V / \AA^{3}, \rho_{\text {xray }} / \mathrm{g} \mathrm{cm}^{-3}$ & $151.33(4), 8.016$ & $160.80(3), 8.452$ \\
Diffractometer & STADI4 (Stoe \& & Smart $1000 \mathrm{~K}$ \\
& Cie), scintillations & (Bruker AXS), \\
& counter & CCD-detector \\
Radiation & MoK $\alpha(\lambda=71.073$ pm), graphite \\
& monochromatated & \\
Absorption correction & $\mathrm{X}-\mathrm{Shape}[13]$ & $\mathrm{SADABS}[14]$ \\
$2 \theta$ range $/^{\circ}$ & 9.06 to 74.82 & 9.04 to 70.08 \\
Index range & $-7 \leq h \leq 7$, & $-7 \leq h \leq 7$, \\
& $-7 \leq k \leq 7$, & $-7 \leq k \leq 7$, \\
Rfelection collected & $-15 \leq l \leq 15$ & $-14 \leq l \leq 14$ \\
Data, $R_{\text {int }}$ & 2976 & 2637 \\
No. of parameters & $183,0.0196$ & $168,0.0535$ \\
$R_{1}\left[F^{2}>2 \sigma\left(F^{2}\right)\right]$ & 8 & 8 \\
$w R\left(\mathrm{~F}^{2}\right)$ & 0.0237 & 0.0255 \\
Extinction coefficient & 0.0631 & 0.0585 \\
$\Delta \rho_{\text {max }}, \Delta \rho_{\text {min }} / \mathrm{e} \AA^{-3}$ & $2.56,-3.31$ & $0.013(2)$ \\
Deposition no. $[15]$ & $\mathrm{CSD}-420340$ & $1.41,-2.02$ \\
& & $\mathrm{CSD}-420341$ \\
\hline & &
\end{tabular}

Table 3. Atomic coordinates and equivalent isotropic displacement parameters $U_{\mathrm{eq}} / \mathrm{pm}^{2}$ for BaAuP and BaAuAs.

\begin{tabular}{lllllll}
\hline Compound & Atom & Site & $x$ & $y$ & $z$ & $U_{\text {eq }}$ \\
\hline BaAuP & $\mathrm{Au}$ & $2 d$ & $1 / 3$ & $2 / 3$ & $3 / 4$ & $150(2)$ \\
& $\mathrm{Ba}$ & $2 a$ & 0 & 0 & 0 & $133(3)$ \\
& $\mathrm{P}$ & $2 c$ & $1 / 3$ & $2 / 3$ & $1 / 4$ & $147(7)$ \\
\hline BaAuAs & $\mathrm{Au}$ & $2 d$ & $1 / 3$ & $2 / 3$ & $3 / 4$ & $114(2)$ \\
& $\mathrm{Ba}$ & $2 a$ & 0 & 0 & 0 & $102(2)$ \\
& $\mathrm{As}$ & $2 c$ & $1 / 3$ & $2 / 3$ & $1 / 4$ & $95(3)$ \\
\hline
\end{tabular}

Table 4. Anisotropic displacement parameters $U_{\mathrm{ij}} / \mathrm{pm}^{2}$ for BaAuP and $\operatorname{BaAuAs}\left(U_{13}=U_{23}=0\right)$.

\begin{tabular}{llllll}
\hline Compound & Atom & $U_{11}$ & $U_{22}$ & $U_{33}$ & $U_{12}$ \\
\hline BaAuP & $\mathrm{Au}$ & $149(2)$ & $U_{11}$ & $151(3)$ & $75(1)$ \\
& $\mathrm{Ba}$ & $126(3)$ & $U_{11}$ & $146(4)$ & $64(1)$ \\
& $\mathrm{P}$ & $115(9)$ & $U_{11}$ & $210(19)$ & $58(5)$ \\
\hline BaAuAs & $\mathrm{Au}$ & $106(2)$ & $U_{11}$ & $132(3)$ & $53(1)$ \\
& $\mathrm{Ba}$ & $96(3)$ & $U_{11}$ & $114(4)$ & $48(2)$ \\
& $\mathrm{As}$ & $63(4)$ & $U_{11}$ & $161(6)$ & $32(2)$ \\
\hline
\end{tabular}

\section{Electrical Resistivity}

Temperature dependent resistivity has been obtained for pressed pellets using van der Pauw method [16]. The ground powders were pressed into $6 \mathrm{~mm}$ diameter by $1 \mathrm{~mm}$ thick pellets, and annealed for $24 \mathrm{~h}$ at $723 \mathrm{~K}$ under argon atmosphere. The pellets were then connected to four probes of the resistivity measurement apparatus. Data were recorded in the temperature range 5-300 $\mathrm{K}$ at $5 \mathrm{~K}$ intervals.

\section{Acknowledgments}

The authors greatfully acknowledge the help of Mrs. S. PrillDiemer for carrying out the synthesis, and Mrs. G. Siegle for resistivity measurements.

\section{References}

[1] M. Jansen, Chem. Soc. Rev. 2008, 37, 1826.

[2] J. Nuss, M. Jansen, Z. Kristallogr. NCS 2002, 217, 313.

[3] C. Hadenfeldt, Z. Anorg. Allg. Chem. 1977, 436, 113.

[4] P. C. D. Dietzel, M. Jansen, Chem. Comm. 2001, 2208.

[5] A.-V. Mudring, J. Nuss, U. Wedig, M. Jansen, J. Solid State Chem. 2000, 155, 29.

[6] R. Hoppe, J. Schneider, J. Less-Common Met. 1988, 137, 85.

[7] H. Nuss, M. Jansen, Angew. Chem. 2006, 118, 4476; Angew. Chem. Int. Ed. 2006, 45, 4369.

[8] A.-V. Mudring, M. Jansen, Angew. Chem. 2000, 112, 3194; Angew. Chem. Int. Ed. 2000, 39, 3066.

[9] J. Nuss, M. Jansen, Z. Anorg. Allg. Chem. 2003, 629, 387.

[10] D. Johrendt, R. Miericke, A. Mewis, Z. Naturforsch. 1996, $51 b, 905$.

[11] V. Saltykov, J. Nuss, M. Konuma, M. Jansen, Z. Anorg. Allg. Chem. 2009, 635, 70 .

[12] G. M. Sheldrick, Acta Crystallogr., Sect. A: Found. Crystallogr. 2008, 64, 112.

[13] Stoe \& Cie GmbH, X-Shape - Crystal Optimisation for Numerical Absorption Correction, version 1.06, Darmstadt, Germany, 1999.

[14] G. M. Sheldrick, SADABS - Bruker AXS area detector scaling and absorption, version 2007/4, University of Göttingen, Germany, 2007.

[15] Further details may be obtained from Fachinformationszentrum Karlsruhe, 76344 EggensteinLeopoldshafen, Germany (fax: (+49)-7247-808-666; e-mail: crysdata(at)fiz-karlsruhe.de, http://www.fizkarlsruhe.de/request for deposited data.html) on quoting the CSD number.

[16] L. J. Van der Pauw, Philips Res. Rep. 1958, 13, 1.

Received: ((will be filled in by the editorial staff)) Published online: ((will be filled in by the editorial staff)) 


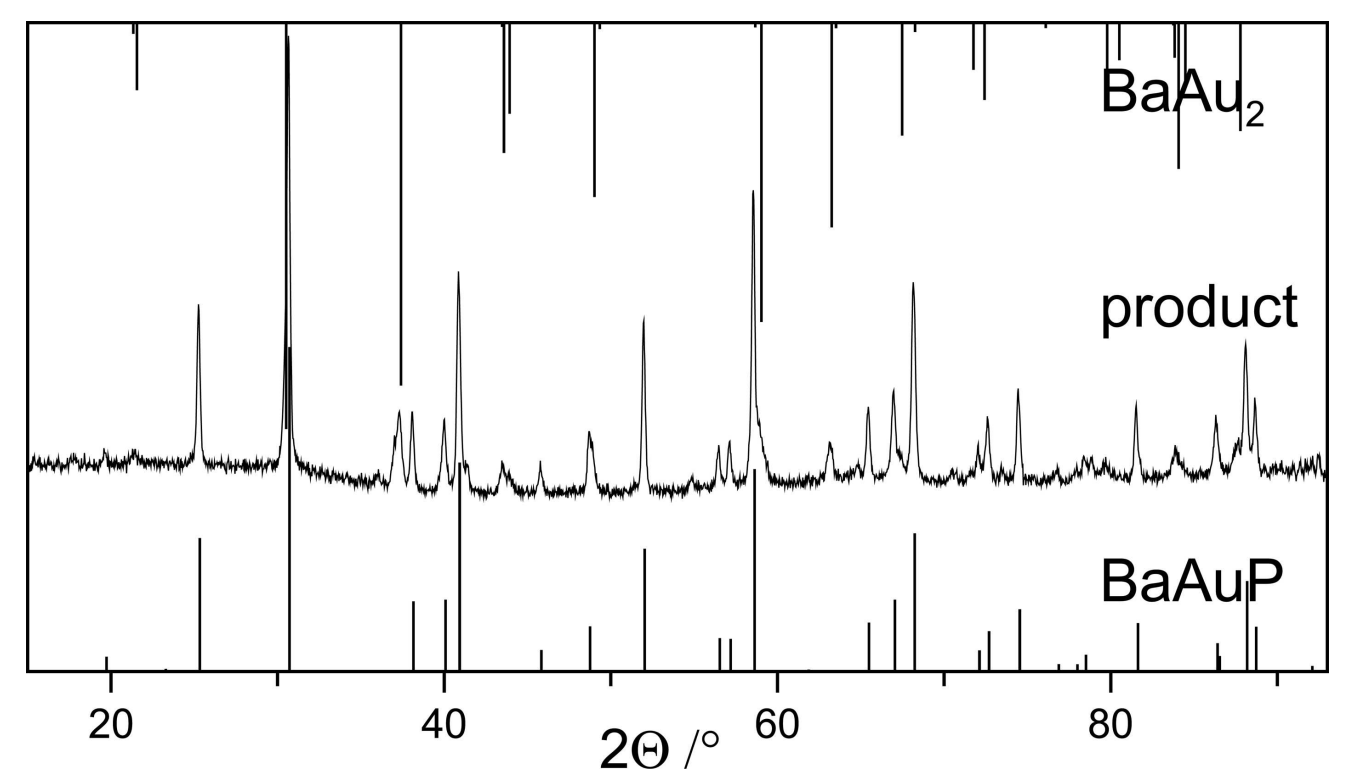

Powder diffraction pattern of the reaction product between $\mathrm{Ba}_{3} \mathrm{P}_{2}$ and $\mathrm{Au}$ (middle), with calculated intensity plots of $\mathrm{BaAu}_{2}$ (top) and BaAuP (bottom). For clarity, the intensities (arbitrary units) are drawn in positive direction for BaAuP and the product, and in negative direction for $\mathrm{BaAu}_{2}$. $120 \times 69 \mathrm{~mm}(600 \times 600 \mathrm{DPI})$ 


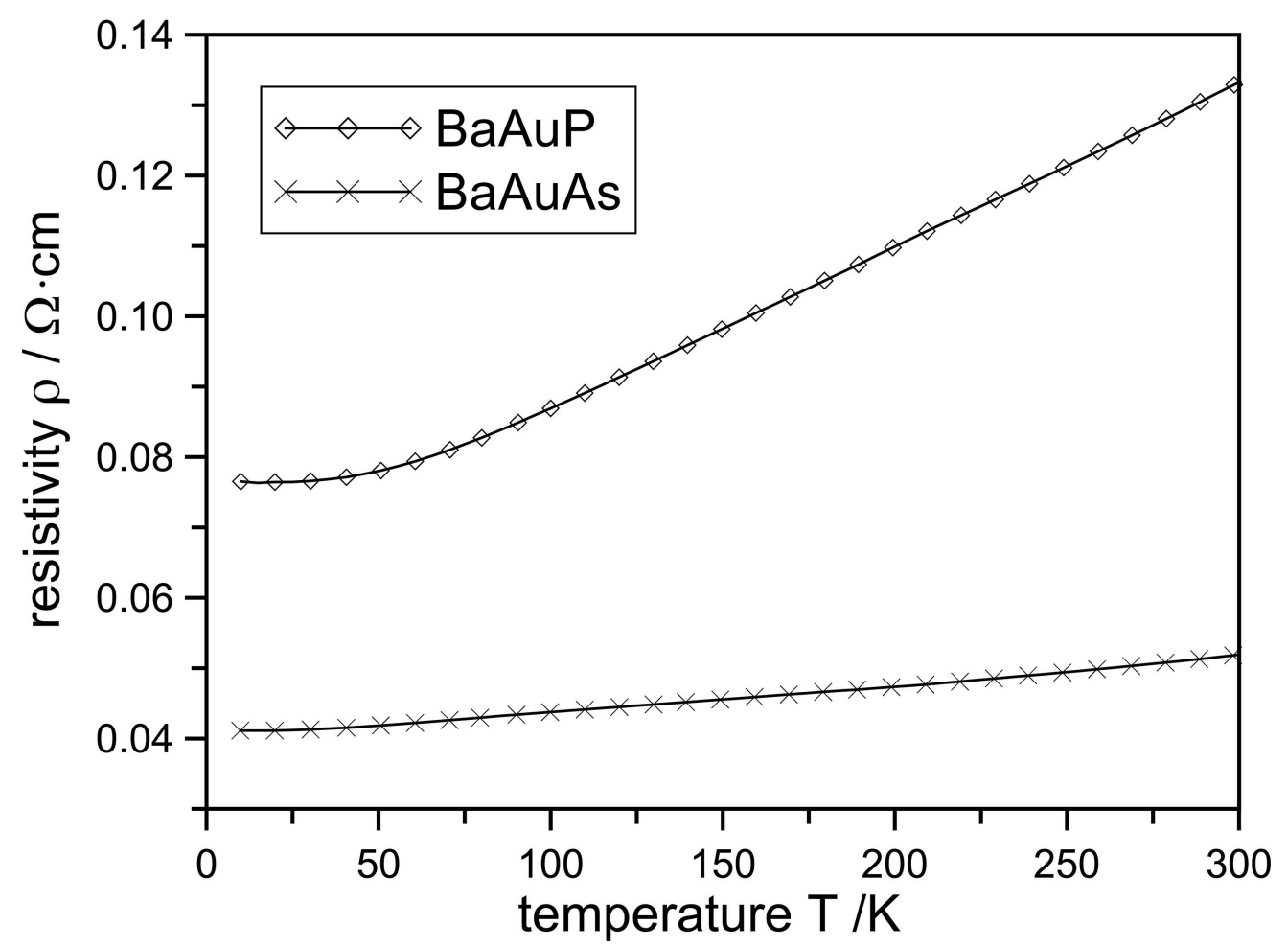

Electric resistivity vs. temperature for BaAuP and BaAuAs. $120 \times 89 \mathrm{~mm}(600 \times 600$ DPI $)$ 


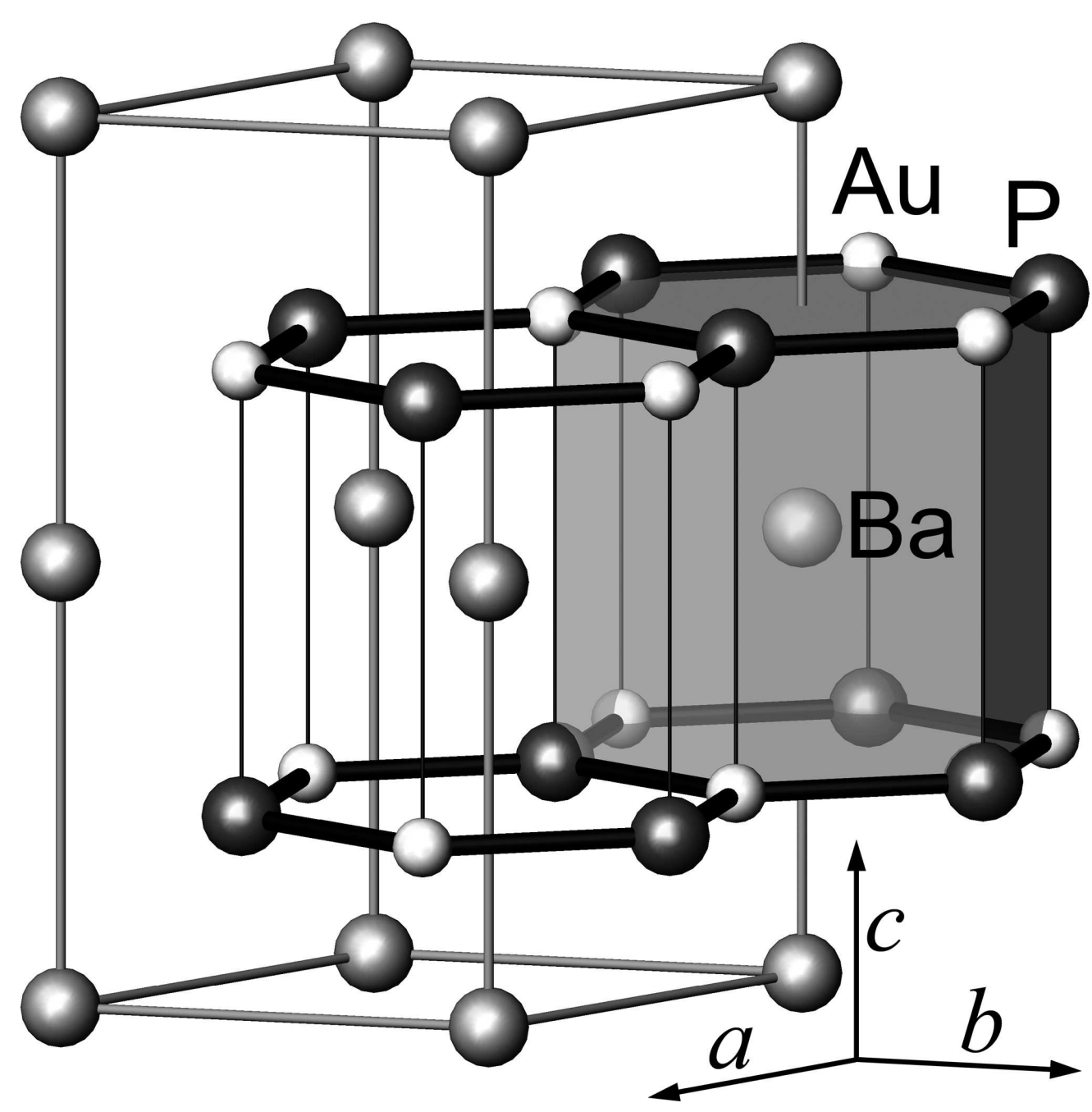

Perspective representation of the crystal structure of BaAuP, with the margins of the unit cell (grey). $85 \times 86 \mathrm{~mm}(600 \times 600 \mathrm{DPI})$ 